\title{
Investigation of Microstructure and Mechanical Properties of Austenite Stainless Steel 304 during Tempering and Cryogenic Heat Treatment
}

\author{
Anitha Lakshmi ${ }^{1}$, Swathi ${ }^{2}$, Tanya Buddi $^{3}$, Ch. Bandhavi ${ }^{4}$, Ram Subbiah $^{5}$ \\ ${ }^{2}$ P.G Student, Dept. of Mechanical Engineering, GRIET, Hyderabad, India. \\ ${ }^{1,, 4}$ Assistant Professor, Dept. of Mechanical Engineering, GRIET, Hyderabad, India. \\ ${ }^{3,5}$ Associate Professor, Dept. of Mechanical Engineering, GRIET, Hyderabad, India.
}

\begin{abstract}
In the present study, the influence of heat treatment (tempering \& cryogenic) on the grain orientation and few important mechanical properties of Austenite Stainless Steel 304 (ASS 304) are examined. The significant mechanical properties like ultimate strength, elongation percentage and surface hardness etc., of the experimented and untreated specimens are computed using pre standard methods and the micrographs of the specimens was conducted using metallurgical microscope. The effect of strain rate ranging from lower to higher strain rates $0.001 \mathrm{~s}-1$ to $0.1 \mathrm{~s}-1$, on true stress - true strain behaviour of tempered austenitic stainless steel 304 is investigated. Experimental results exhibited that the mechanical behaviour of ASS 304 can be reformed and improvised by several heat treatment procedures for a specific application. The results showed that the cryogenic treated specimens indicate lowest tensile strength, hardness and highest percent of elongation value compared with tempered specimen gave the maximum tensile strength, hardness and minimum percent of elongation in length value.
\end{abstract}

\section{Introduction}

Heat Treatment of engineering materials is a combination of coordinated heating along with cooling of a specific alloy or solid metal such that it produces required microstructure and desirable mechanical properties like stiffness, yield strength, ultimate strength, Elastic modulus, percentage of elongation, strain hardening and strength co-efficient [1]. Cryogenic and tempering are considered the important effective heat treatments frequently used to alter the micrograph and mechanical properties of metals and alloys, especially steels; it is used in engineering materials where elongations and appreciable tensile strength are needed [2]. Technologically, cryogenic implies the study and use at extremely low temperatures of materials (or other requirements). Given that the LNG storage holds or infrastructure insulation device is subjected to cryogenic temperature, it is usually beneficial to use austenitic stainless steels because their cryogenic mechanical properties demonstrate superior durability, e.g. high strength, ductility and resilience. [3]. In tempering the material is heated below critical point of austenitic stainless steel 304 and this is followed by air cooling [4]. The stainless austenitic steels are rich in nickel and chromium content to improve specific mechanical properties. Most of this is used in travel, i.e. automotive. Owing to its outstanding corrosion resistance in seawater conditions. Austenitic Stainless
Steel-304 (ASS-304) sheets are commonly used in the area of Navy and Nuclear Applications. Due to its low carbon content contributes for increased wear and friction properties and is less susceptible to corrosion between grain boundaries of different atoms [5].

So the degree of its application would be determined by its heat treatment conditions. A. Tukur et al., researched the ideal heat treatment technique for stainless steel AISI 304 and proposed that specimens have the maximum hardness value at $666^{\circ} \mathrm{C}$ [6]. The ideal temperature to avoid grain growth on annealed 304 stainless steels (solution conditioned) is found to be $666^{\circ} \mathrm{C}$. In his work, Nadum Ibrahim Nasir et al. picked a sample of stainless steel type 304, where thermal treatment is performed at $(1050,1100,1150)^{\circ} \mathrm{C}$ respectively, after that tempering process is performed at $350^{\circ} \mathrm{C}$ and investigated the thermal treatment enhanced mechanical properties with the exception of shock examination and the best properties appeared at $1100^{\circ} \mathrm{C}$ [7]. Kyung Jun Lee at al., studied the material behaviour of ASS at various ranges of cryogenic temperatures with help of Universal Testing System, fitted with a cryogenic chamber, and described that strength-related properties appear to increase with temperature decrease [8] kosaraju Satyanarayana has assessed the material properties depending upon the observational data obtained from isothermal uniaxial tensile tests conducted at an interval of $25^{\circ} \mathrm{C}$ within a range of $0^{\circ} \mathrm{C}$ to $-50^{\circ} \mathrm{C}$ and at three sheet orientations $(0,45,90)$ degrees to the

\footnotetext{
* Corresponding author: anitha.akkireddy@gmail.com
} 
rolling direction and punch velocity $(0,45,90)$ degrees to the rolling direction and punch velocity $(3,5,7)$ $\mathrm{mm} / \mathrm{min}$ are selected [9]. Anitha Lakshmi et al., has done tensile and formability tests on annealed heat treated Austenitic stainless steel and aluminium alloy specimens [10-13]. Though there are more developments in ASS 304 yet some gap exists for better application of ASS304. Thus, ASS-304 material is investigated under different heat treatment condition for enhancement in ductility and metallographic studies. Tanya Buddi et al., conducted tests on ASS $316 \mathrm{~L}$ at elevated and sub-zero temperatures to evaluate material properties, formability, microstructure study and corrosion resistance study [1719].

\section{Experimental Procedure}

The chemical composition of ASS 304 sheets used in the present investigation is analyzed by a spectrometer analysis in Jyothi laboratories. [14]. These chemical composition results are shown in Table.1. The ASS 304 sheet is cut into sub sized tensile specimens following ASTM standards using wire-cut EDM (electro-discharge machining) process for good accuracy and finishing.

Table 1. Weight percentage chemical composition of ASS 304

\begin{tabular}{|c|c|}
\hline Material & $\begin{array}{c}\text { Weight \% } \\
\text { Composition }\end{array}$ \\
\hline $\mathrm{C}$ & 0.017 \\
\hline $\mathrm{Si}$ & 0.34 \\
\hline $\mathrm{Mn}$ & 1.26 \\
\hline $\mathrm{P}$ & 0.019 \\
\hline $\mathrm{S}$ & 0.004 \\
\hline $\mathrm{Cr}$ & 18.66 \\
\hline $\mathrm{Ni}$ & 8.02 \\
\hline
\end{tabular}

The heat treatments are performed in the cryogenic freezer and tempering chambers. Cryogenic chamber shown in Fig.1 can accommodate temperature upto $-180^{\circ} \mathrm{C}$ is connected to nitrogen plant which generates liquid nitrogen, with the help of transfer lines supply of liquid nitrogen to the cryogenic chamber. Samples are cryogenic treated at temperatures $-80^{\circ} \mathrm{C}$ and $-120^{\circ} \mathrm{C}$ for 4 hours shown in Fig.3. Tempering chamber capable to perform the experiments at higher temperatures upto $800^{\circ} \mathrm{C}$ is shown in Fig.2. Samples are heated to $400^{\circ} \mathrm{C}$ and $600^{\circ} \mathrm{C}$ for 4 hours respectively as shown in Fig.4.

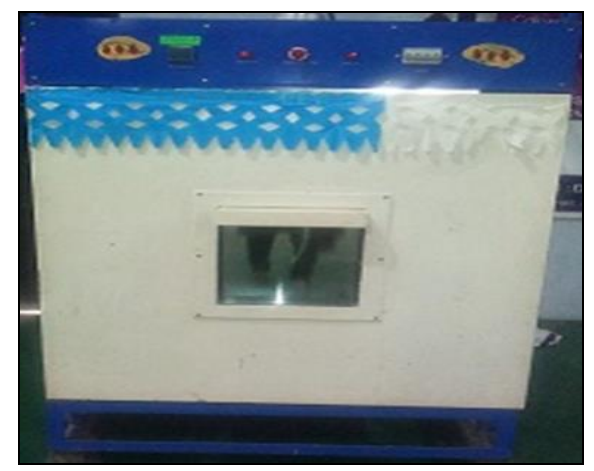

Fig. 1. Cryogenic treatment set up

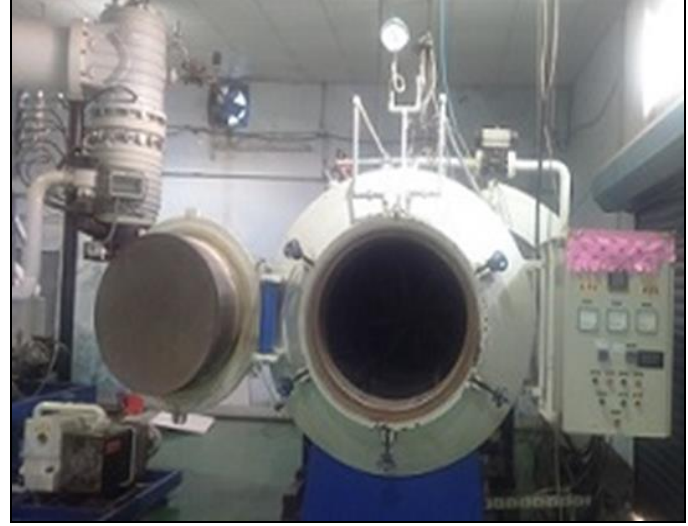

Fig. 2. Tempering treatment set up

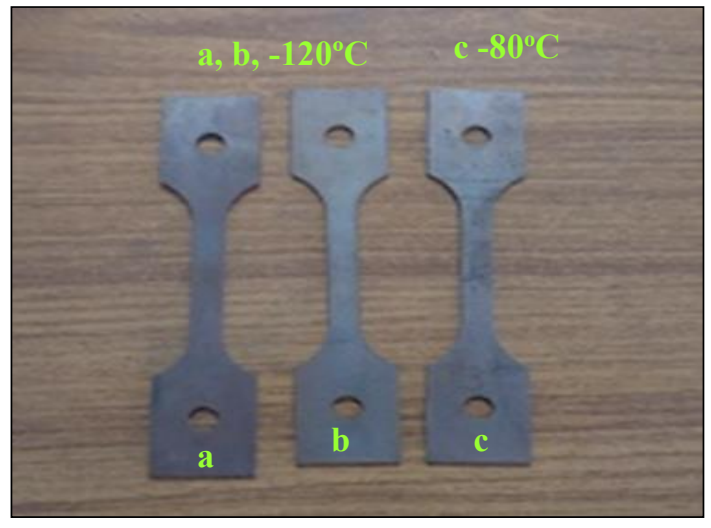

Fig. 3. Samples cryogenic treated at $-80^{\circ} \mathrm{C} \&-120^{\circ} \mathrm{C}$

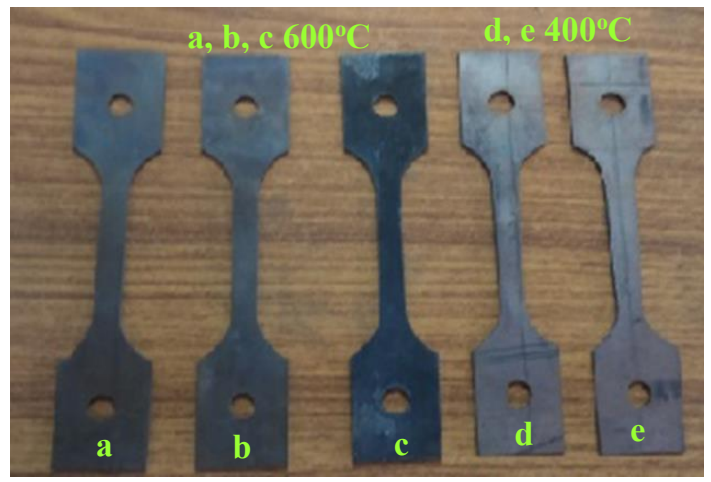

Fig. 4. Samples tempered at $400^{\circ} \mathrm{C} \& 600^{\circ} \mathrm{C}$

\subsection{Tensile Test}

Uniaxial tensile testing on Universal Measuring Machine-UTM used at room temperature in Fig.5 has determined the tensile properties for the material. The tensile testing is carried out using the Universal Testing Machine (UTM) called ELECTRA 50 model, which has $5 \mathrm{KN}$ charging capacity. The unit has a split furnace at the top with the capacity to do high temperature tensile checking. Within the furnace heating will occur up to $1000^{\circ} \mathrm{C}$. Spacers made of Inconel are used to rigidly secure the tensile specimen between the slots in the puller rod. Such spacers avoid dislocation of the specimen after pulling. The tensile specimen is put between test machine dies as shown in Fig.6. 


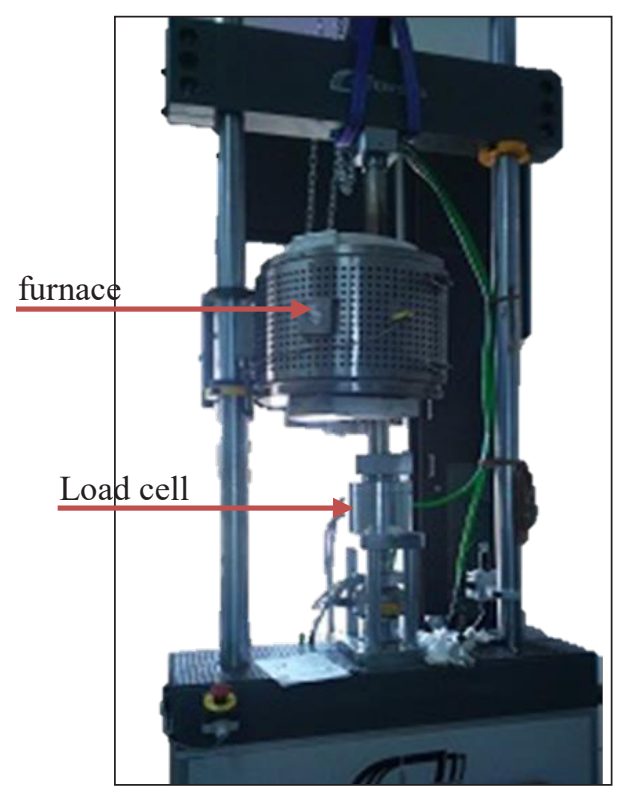

Fig. 5. Universal Testing Machine (ELECTRA 50)

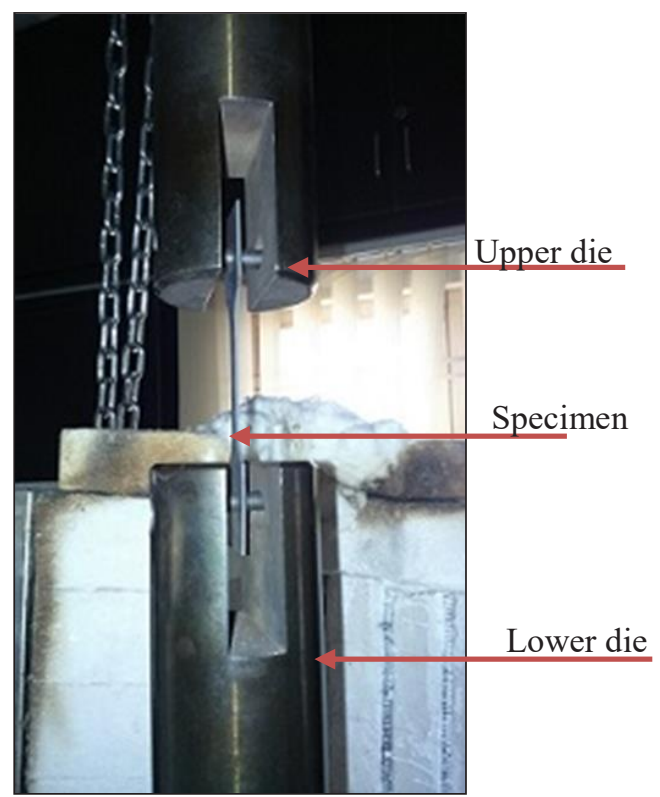

Fig. 6. Specimen gripped in between the dies of Testing Machine

\subsection{Microstructure Studies}

The samples of ASS-304 cryogenic treated tempered and untreated samples.are etched using Oxalic acid. Fractured specimens are seen under meta scope metallurgical microscope (magnification 100X) and their micrographs are captured. The examination process is repeated for cryogenic treated, tempered and untreated samples. The microstructure images $100 \mathrm{X}$ are uploaded to Met Image Lx metallographic software to evaluate the grain size and are shown in Fig.7.

\subsection{Hardness Test}

Micro hardness of the sample is evaluated by loading an indenter using Vickers indenter into the top surface of the material with $50 \mathrm{gm}$ load; the depressions are so small in size that they measured with a metallurgical microscope Fig 7 represents the comparison of hardness for cryogenic treated, tempered and untreated specimen.

\section{Results and Discussion}

Properties like Ultimate Tensile Strength (UTS), Yield stress, Percentage elongation, Young's modulus, Strain hardening and Strength co-efficient are measured through tensile test for cryogenic treated, tempered sample and untreated sample. The resulting values obtained from the tensile test are plotted. The data clearly shown in Fig.8 marks an improvement in ultimate strength, strain hardening, young's modulus, and strength co-efficient; whereas a decrease in elongation and yield strength is observed with increase in tempering temperature. It is observed that tempering at $600^{\circ} \mathrm{C}$ reduces the amount of retained austenite; this makes the austenite less stable. This causes the ultimate strength to increase slightly and also causes decrease in elongation.
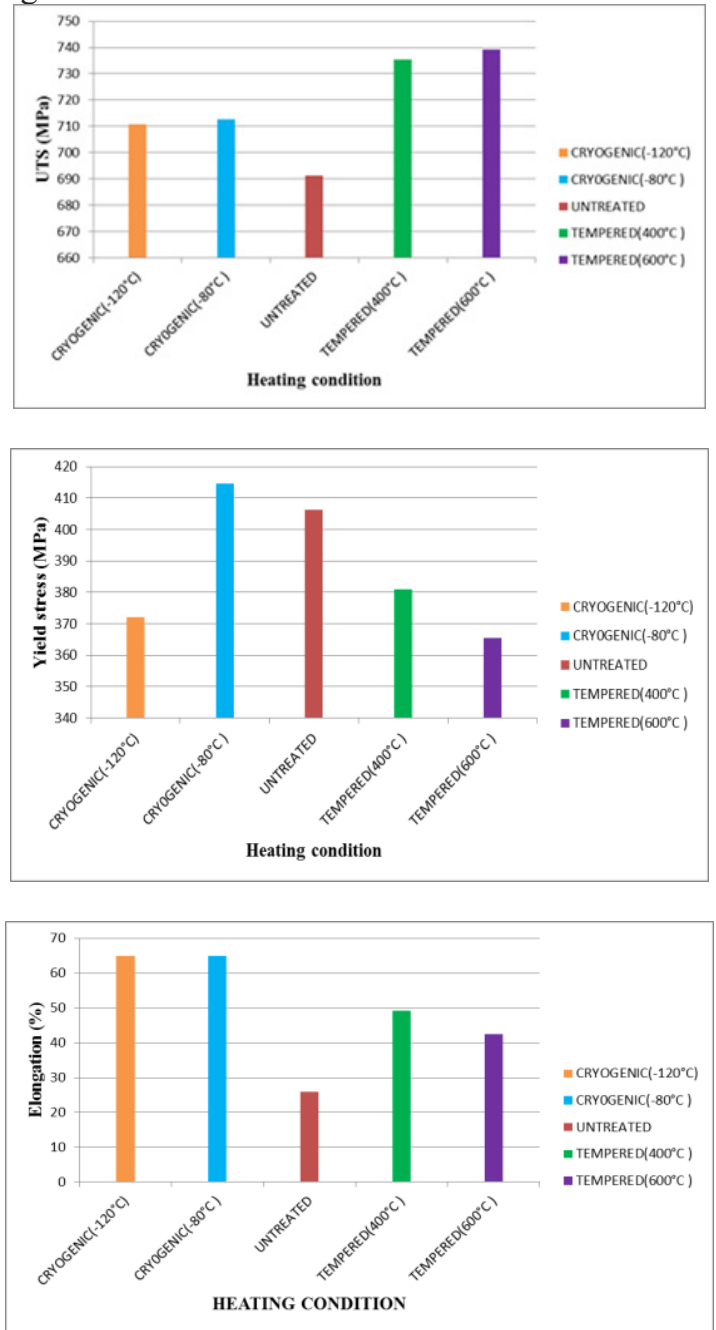

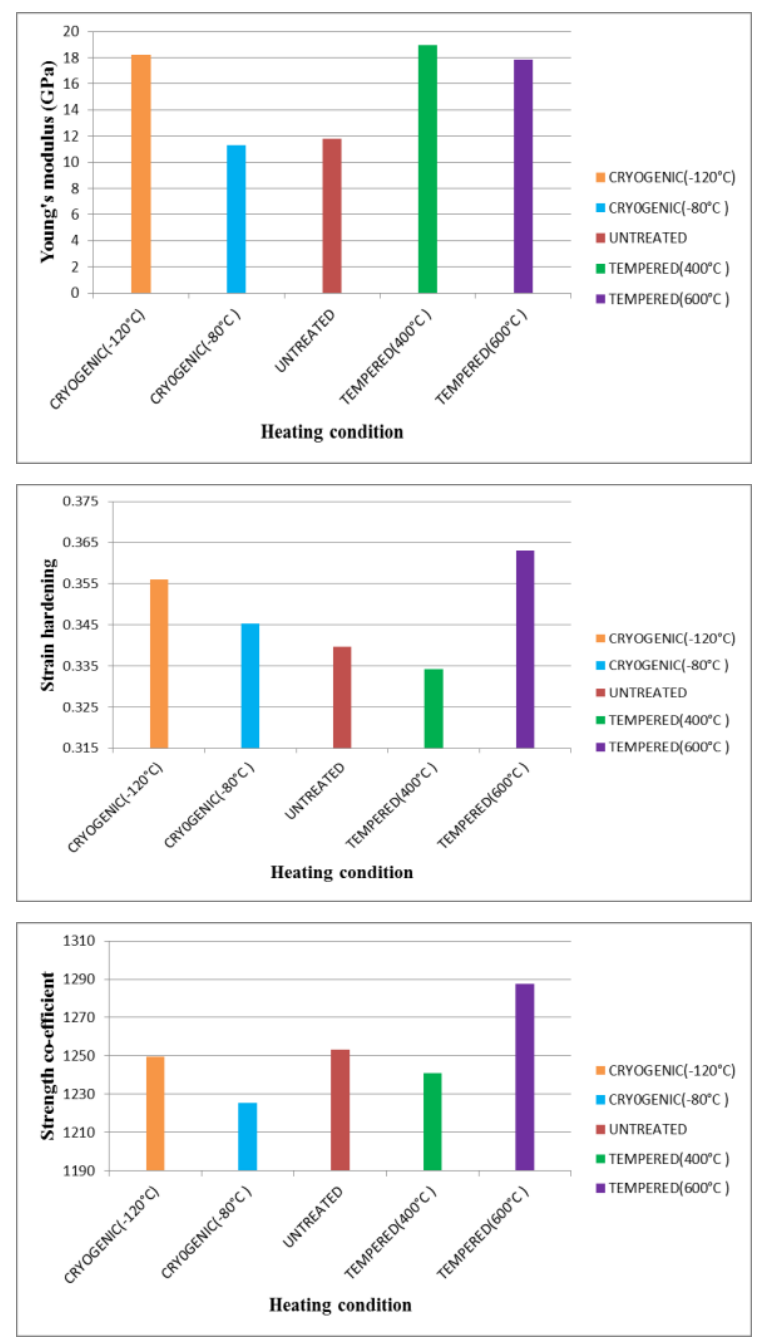

Fig. 7. Tensile properties vs Heating condition

Cryogenic treated samples show little improvement in properties compared to untreated sample. Elongation is greater in cryogenic heat treatment than untreated and tempering heat treatment that shows the higher ductility property in cryogenic treated samples.

In this investigation tests are carried to know the effect of tensile properties by varying the strain rates on tempered samples. Tensile results are reported for strain rates within the range $0.001 \mathrm{~s}^{-1}$ and $0.1 \mathrm{~s}^{-1}$. The tensile properties like yield stress, Young's modulus $\left(\mathrm{Y}_{\mathrm{s}}\right), \%$ elongation, Ultimate Tensile Strength (UTS), strain hardening coefficient (n) and strength coefficient calculated using formulae are plotted with bar graphs in Fig. 9 to be linearly dependent on the logarithm of strain rate while tensile strength, elongation, material constant and strength co-efficient are shown to decrease with increasing loading rate prior to approaching a minimum value.

The decrease in UTS for ASS 304 occurs because as the strain rate increases, the heat remains higher and the tensile measure becomes adiabatic at about $0.1 \mathrm{~s}^{-1}$. Since martensite is the stronger state, a decrease of the volume fraction due to the rise of the specimen temperature results in a corresponding decrease in strength intensity. Lowest strain rates give the highest strengths. Selfheating of a tensile material does not happen at lower strain intensity and transforming of austenite into the tougher martensite is uninhibited. However, the resilience of austenite decreases as heating happens at a higher strain rate, which prevents the transformation. Furthermore, SFE improves with temperature, which decreases the number of density of planar slip elements, e.g., folding faults, slip lines, and slip band boundaries, all associated with martensite nucleation.

Similar to UTS variation, ASS 304 elongation is highest at low strain levels and then declines as strain levels increase to $0.1 \mathrm{~s}^{-1}$. Unlike UTS, the loss of UEL (uniform elongation) is due to higher specimen heating and an associated loss in austenite work hardenability as well as a loss in the volume of martensite caused by strain.
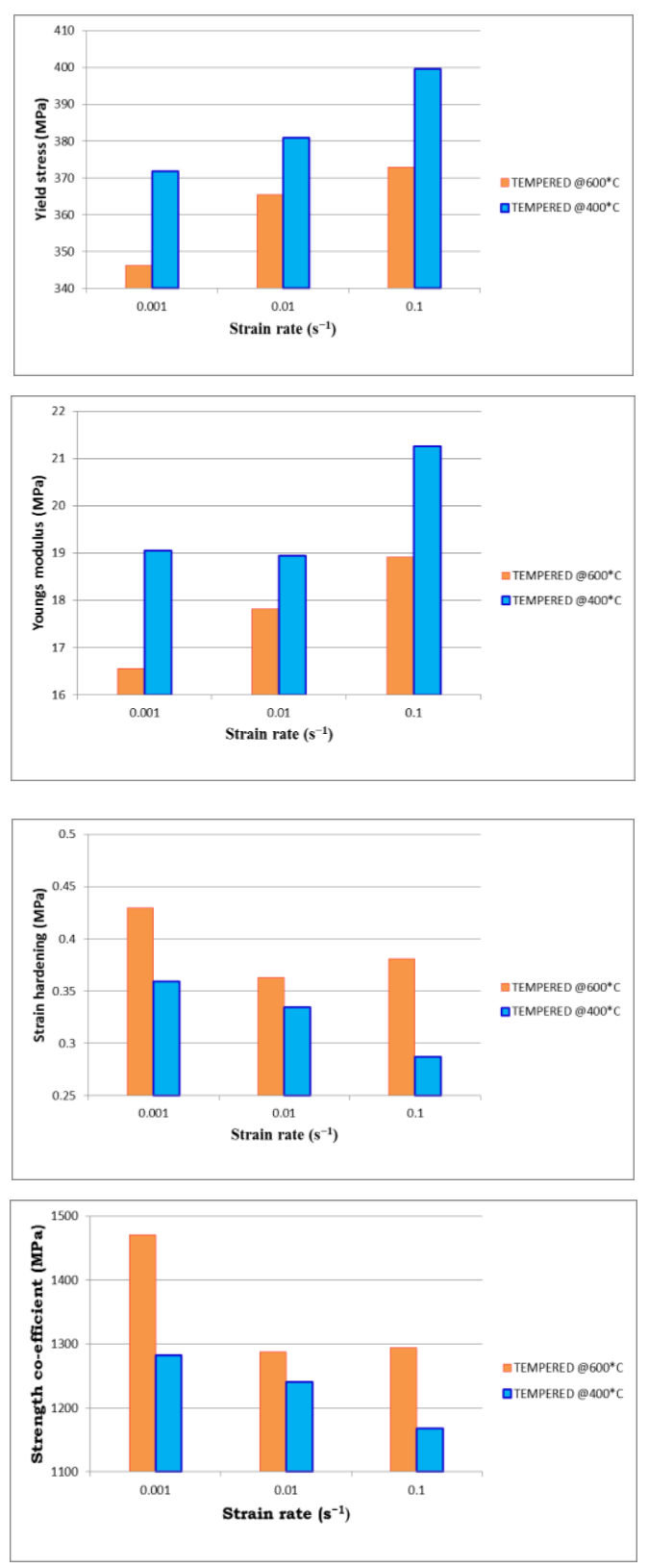

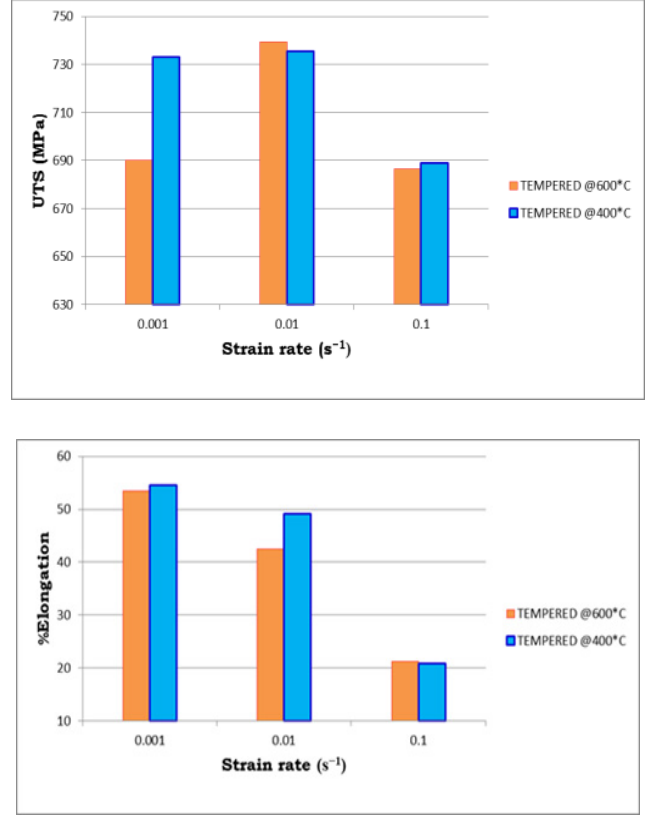

Fig. 8. Comparison of mechanical properties for tempered samples by varying strain rates

The microstructure shown in Fig.9 reveals that there is no much difference in the microstructure of untreated sample and cryogenic heat-treated samples. The austenite grains are absolutely tiny but expand in size as time and temperature increase. Steels carried at temperatures only above the (upper) critical the grain size should remain low. Nevertheless, at higher temperatures, various steels showed large variance in grain size, based on the chemical composition and steel producing methods (deoxidation and previous treatment) [15-16]. Fine-grain microstructure of cryogenic samples do not harden as strongly and have less potential to break than comparable tested coarse-grain steels. The micrographs at tempered condition show formation of perfect grain boundaries with increase in the temperature showcasing maximum strength.
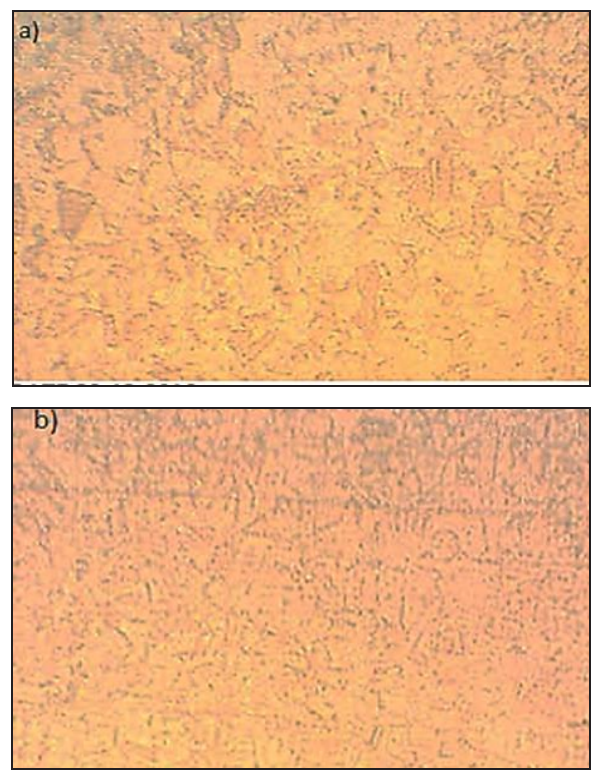
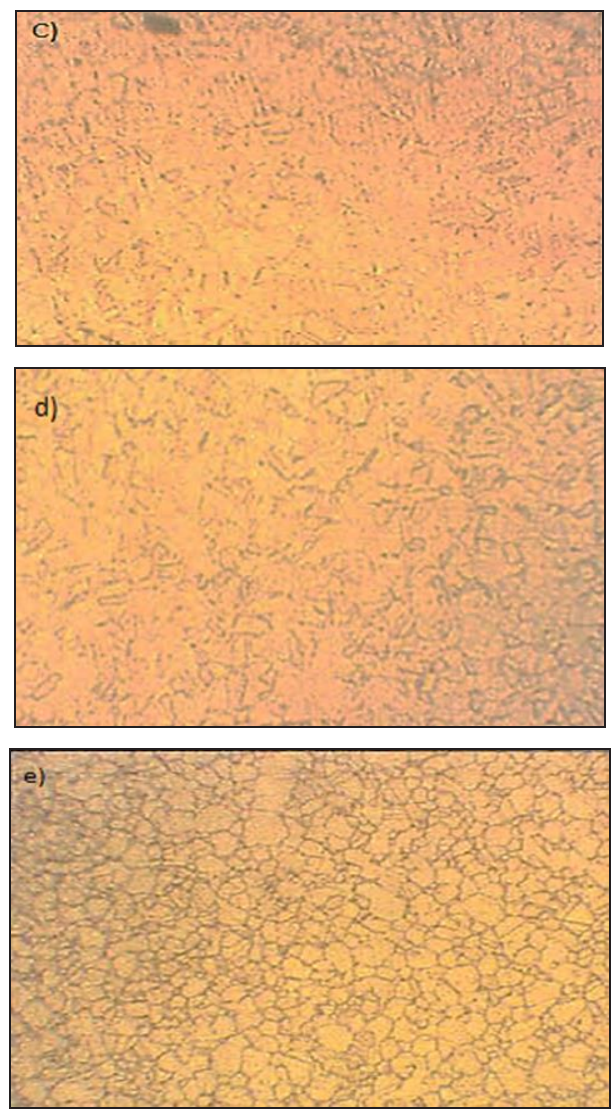

Fig. 9. Microstructure (100X) of ASS 304 (a) untreated (b) cryogenic treated at $-80^{\circ} \mathrm{C}(\mathrm{c})$ cryogenic treated at $-120^{\circ} \mathrm{C}(\mathrm{d})$ Tempered at $400^{\circ} \mathrm{C}$ (e) Tempered at $600^{\circ} \mathrm{C}$

Based on the comparison of hardness value from Fig.10 it is noticed that sample tempered at $400^{\circ} \mathrm{C}$ which show a slightly higher level of hardness over the cryogenic temperature range and untreated sample. The amount of hardness in samples is due to the fine grain structure of tempered sample. The finer the grain structure the higher the hardness. In the present investigation hardness of samples increased with performance of tempering heat treatment.

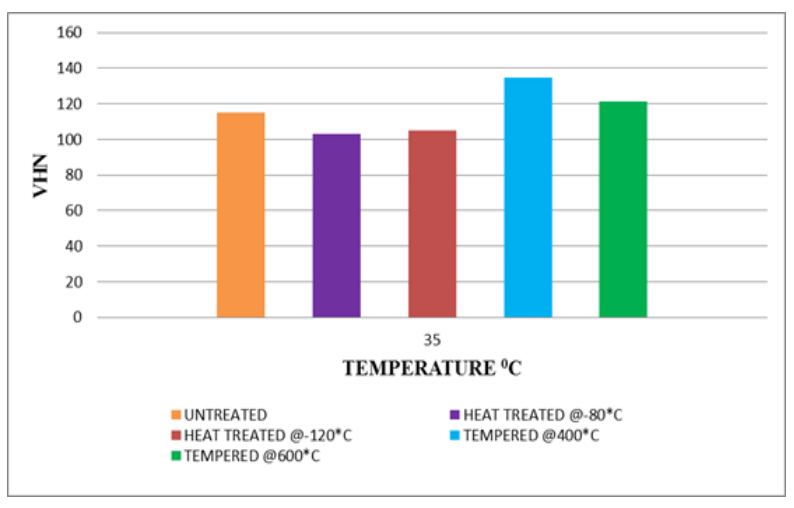

Fig. 10. Comparison of Hardness value

\section{Conclusion}

Based on experimental results, few conclusions are drawn: 
- Mechanical properties are tested using UTM for various cryogenic treated, tempered and untreated samples. It is observed that for tempered samples at $600^{\circ} \mathrm{c}$ few properties show improvement. As comparing elongation property for all samples, cryogenic samples shows better results.

- At various strain rates the effect of tensile properties is investigated. It is observed that with increasing the strain rates modulus and yield stress are linear whereas strength coefficient, elongation, tensile strength and material constant are decreasing.

- At $400^{\circ} \mathrm{c}$ tempered samples have little high level of hardness when compared with cryogenic and untreated samples due to the fine grain structure.

\section{References}

1. Fadare, D. A., T. G. Fadara, and O. Y. Akanbi. "Effect of heat treatment on mechanical properties and microstructure of NST 37-2 steel" (2011).

2. Gill, Simran Preet Singh, et al. "Metallurgical principles of cryogenically treated tool steels-a review on the current state of science", The International Journal of Advanced Manufacturing Technology 54.1-4, 59-82, (2011)

3. Blanchat, Thomas K., Marion Michael Hightower, and Charles Morrow, "LNG Ship Insulation Experiments Using Large LNG Pool Fire Boundary Conditions". No. SAND2013-0426C. Sandia National Lab. (SNL-NM), Albuquerque, NM (United States), (2013).

4. Padilha, A. F., R. L. Plaut, and P. R. Rios. "Stainless steels heat treatment (chapter 12). OnI: Totten GE", Steel heat treatment, 695-739.

5. Jayahari, L., Sasidhar, P.V., Reddy, P.P., BaluNaik, B., Gupta, A.K., Singh, S.K., "Formability studies of ASS 304 and evaluation of friction for Al in deep drawing setup at elevated temperatures using LSDYNA" Journal of King Saud University Engineering Sciences, 26 (1), 21-31, (2014)

6. Tukur, S. A., et al. "Effect of heat treatment temperature on mechanical properties of the AISI 304 stainless steel." Intl J Innov Res Sci Eng Technol, 3: 9516-9520, (2014).

7. Nasir, Nadum Ibrahim. "Effect of Heat Treatment On The Mechanical Properties of Stainless Steel Type 304", Inter-national J. Scrientific Eng,. Res 3: 87-93, (2015).

8. Lee, Kyung Jun, et al., "A new constitutive model of austenitic stainless steel for cryogenic applications", Computational Materials Science, 46(4), 1152-1162, 2009

9. Satyanarayana Kosaraju, Swadesh Kumar Singh, Tanya Buddi, Anil Kalluri \& Ahsan Ul Haq, "Evaluation and characterisation of ASS316L at sub-zero temperature", Advances in Materials and Processing Technologies, 6:2, 445455, DOI: 10.1080/2374068X.2020.1728650, (2020)
10. Reddy, D. Mahesh, A. Anitha Lakshmi, and Ahsan ul Haq, "Experimental Taguchi approach and GrayTaguchi optimization on mechanical properties of aluminum 8011 alloy sheet under uniaxial tensile loads", Materials Today: Proceedings, 19: 366-371, (2019)

11. Harshini, Dharanikota, et al. "Comparative study on mechanical behavior of ASS 316L for low and high temperature applications." Materials Today: Proceedings, 19, 767-771, (2019)

12. Lakshmi, A. Anitha, Ch Srinivasa Rao, and Tanya Buddi. "Prediction of Superplasticity Of Austenitic Stainless Steel-304 At Hot Working Temperatures." Materials Today: Proceedings, 18, 2814-2822, (2019)

13. Lakshmi, A. Anitha, et al., "Forming limit diagram of AISI 304 austenitic stainless steel at elevated temperature: experimentation and modelling." Int. J. Mech. Eng. Technol. (IJMET), 9.12 (2018): 403407.

14. Lakshmi, A. Anitha, et al., "Prediction of mechanical properties of ASS 304 in superplastic region using artificial neural networks", Materials Today: Proceedings, 5.2, 3704-3712, (2018)

15. Govardhan, D., Kumar, A.C.S., Murti, K.G.K., Madhusudhan Reddy, G, "Characterization of austenitic stainless-steel friction surfaced deposit over low carbon steel", Materials and Design, 36, pp. 206-214, (2012).

16. Lin, Y.C., Wu, F., Wang, Q.-W., Chen, D.-D., Singh, S.K., "Microstructural evolution of a Ni-FeCr-base superalloy during non-isothermal two-stage hot deformation Vacuum", 151, 283-293, (2018)

17. Baloji Dharavath, Ahsan ul Haq, Dinesh Varma M., Tanya Buddi, Swadesh Kumar Singh \& M. T. Naik, Comparative study of ASS $316 \mathrm{~L}$ on formability at room temperature and super plastic region, Advances in Materials and Processing Technologies, 6:2, 464-475,

DOI: 10.1080/2374068X.2020.1728648, (2020)

18. K. V. Durga Rajesh, Tanya Buddi, P. Rahul Kanth \& Kosaraju Satyanarayana "Microstructural and corrosion resistance study on plasma arc welded joints of AISI 304 and AISI 316", Advances in Materials and Processing Technologies, 6:2, 241257, DOI: 10.1080/2374068X.2020.1732158, (2020)

19. AU Haq, AK Kavit, T Rao, Tanya Buddi, D Baloji, K Satyanarayana, SK Singh, "Evaluation and optimization of material properties of ASS 316L at elevated temperatures using Response Surface Methodology", Elsevier Materials Today: Proceedings, 18, 4589-4597, (2019) 